\title{
IMPORTÂNCIA DOS CURSOS EXTRACURRICULARES NA FORMAÇÃO PROFISSIONAL DOS ACADÊMICOS DO CURSO TÉCNICO EM AGROPECUÁRIA
}

\author{
Karina Gutierrez \\ McGill University, Canadá. \\ Joabel Tonellotto dos Santos \\ Universidade Federal de Santa Maria, Brasil. \\ Matheus Pedrotti De Cesaro \\ Universidade Federal de Santa Maria, Brasil. \\ Paulo Roberto Antunes da Rosa \\ Universidade Federal de Santa Maria, Brasil. \\ Leila Maria Araújo Santos \\ Universidade Federal de Santa Maria, Brasil.
}

\begin{abstract}
Resumo
Cursos extracurriculares são uma oportunidade de praticar e aprender assuntos muitas vezes não abordados no decorrer de um curso. Este trabalho objetivou verificar a percepção dos discentes do início e final do Curso Técnico em Agropecuária do Colégio Politécnico da UFSM em relação aos cursos extracurriculares. Por meio de questionário foi observado que os estudantes consideram os cursos extracurriculares importantes para a formação profissional. Também foi observado que grande parte dos estudantes já participou de atividades semelhantes. Os resultados obtidos demonstram a preocupação dos alunos com o futuro profissional e também o papel fundamental de agências financiadoras de atividades na formação qualificada dos estudantes.

Palavras-chave: aprendizagem, práticas, currículo, Pronatec.
\end{abstract}

\section{THE IMPORTANCE OF EXTRACURRICULAR COURSES IN PROFESSIONAL TRAINING OF STUDENTS OF THE AGRICULTURE TECHNICAL COURSE}

\section{Abstract}

Extracurricular courses are an opportunity to practice and learn subjects not often addressed in the curriculum. This study aimed to determine the perceptions of students from the beginning and end of the Agriculture Technical Course of Colégio Politécnico of UFSM regarding extracurricular courses. Through questionnaire was observed that students from both semesters consider extracurricular courses an important methodology for the training. In addition was observed that 
most students have already participated in similar activities. These results indicated interest and the preoccupation of the students with the professional future and the fundamental role of financial agencies in the training of qualified students.

Key-words: learning, practices, curriculum, Pronatec. 


\section{Introdução}

competitividade no mercado de trabalho passou a depender da capacidade
da empresa produzir, desenvolver ou incorporar inovações e diferenciais e
promover a formação dos seus recursos humanos, ou seja, profissionais cada vez mais qualificados. Os cursos técnicos, amplamente difundidos atualmente, são uma oportunidade de formação qualificada para melhor atender o mercado de trabalho, gerando renda para o trabalhador e qualificação de serviço para a indústria (Deluiz, 2001). A grande dificuldade das empresas em conseguir contratar pessoas qualificadas para preencher as vagas disponíveis coloca em questão a eficiência do processo de formação e qualificação destes profissionais.

Entrar no ambiente de trabalho familiarizado com as técnicas a serem executadas é um diferencial do profissional que busca credibilidade frente à empresa contratante, já que em momentos iniciais de sua contratação existe uma imprevisibilidade em relação a sua permanência na indústria. Dessa forma, um dos grandes desafios das escolas técnicas é o equilíbrio entre o aprendizado teórico e prático. Como forma de solucionar esse problema e contribuir para a qualificação dos estudantes algumas instituições priorizam políticas voltadas para a contratação de professores com formação didático-pedagógica e experiência prática (Morosini, 2000), porém, esta política educacional de forma isolada não atende as necessidades de um mercado de trabalho amplo e em constante processo de atualização.

A inclusão de atividades práticas e cursos extracurriculares no decorrer do curso podem ser estratégias que propiciem melhor desenvolvimento profissional e formação de um perfil multiprofissional (Gondin, 2002; Pereira, et al, 2011). Considerando a deficiência da formação profissional e as lacunas deixadas pela formação destes profissionais, o objetivo deste trabalho foi verificar qual a percepção dos discentes do Curso Técnico em Agropecuária do Colégio Politécnico da Universidade Federal de Santa Maria em relação aos cursos extracurriculares. Para avaliar este objetivo, foram aplicados questionários para os alunos do segundo e quarto semestre com a finalidade de se verificar se existem diferenças de percepção entre alunos do início e fim do curso técnico.

\section{Referencial teórico}

As escolas técnicas são instituições de educação superior, básica e profissional, pluricurriculares, especializadas na oferta de educação profissional e tecnológica nas diferentes modalidades de ensino, tendo como base conhecimentos técnicos e tecnológicos às suas práticas pedagógicas (Ramos, 2011).

Com a expansão das escolas técnicas no Brasil (lei n. 11.892/2008), aumentou a demanda pela qualidade da formação técnica e tecnológica em nível médio ou pós-médio, portanto, seus egressos necessitam de maior qualificação para inserção no mercado de trabalho. Neste contexto, o governo federal criou, em 2011, o Programa Nacional de Acesso ao Ensino Técnico e Emprego - Pronatec, para possibilitar a oferta de um maior número de cursos que complementem a formação técnica. O Pronatec tem como um de seus objetivos expandir, interiorizar e democratizar a oferta de cursos de educação profissional técnica de nível médio e de cursos de formação inicial e continuada ou qualificação profissional presencial e a distância. 
A pesquisa foi realizada no Colégio Politécnico da Universidade Federal de Santa Maria, que segundo seu projeto político-pedagógico, tem como missão promover a formação integral do cidadão e oferecer-lhe condições de conhecer, desenvolver, difundir e aplicar ciência e tecnologia.

Sendo assim, os cursos extracurriculares estão em consonância com a missão citada e com os objetivos do Colégio Politécnico da Universidade Federal de Santa Maria: ministrar o ensino profissional de nível básico, técnico e tecnológico, buscando sempre habilitar seus egressos a desempenharem atividades variadas no mundo do trabalho, abrangendo a capacitação técnica e a formação do homem integral, preocupado com as questões sociais e ambientais do mundo em que vivemos.

Um dos principais aspectos dos cursos extracurriculares é a oportunidade de propiciar o contato com diversas áreas que muitas vezes não são abordadas ou são abordadas superficialmente nos cursos. Um estudo realizado com estudantes egressos e ingressos do Curso de Administração da Universidade Federal de Santa Catarina avaliou qual a contribuição do desenvolvimento de atividades extracurriculares para o alcance de seus objetivos profissionais. Os dados demonstram que os alunos egressos planejam suas carreiras muito mais do que os alunos ingressos, devido à preocupação com a inserção no mercado de trabalho. Porém, os alunos ingressos também consideram o planejamento de carreira um ponto essencial (Pereira, et al., 2001).

Outra pesquisa envolvendo estudantes do curso de Medicina avaliou a importância das atividades extracurriculares na formação profissional. Os dados revelaram que os estudantes de Medicina identificam seu envolvimento com atividades extracurriculares como uma tentativa de preencher lacunas curriculares, integrar-se com colegas, suplementar o curso, obter bem-estar, atender a indagações profissionais (Peres, 2006).

Levando em consideração a valorização da formação extracurricular pelas instituições, estudantes e pelos órgãos financiadores, o objetivo deste trabalho foi avaliar a percepção que os alunos do início e fim do Curso Técnico em Agropecuária do Colégio Politécnico da Universidade Federal de Santa Maria têm a respeito dos cursos extracurriculares. Uma vez que os cursos técnicos possuem uma grande carga horária e foco nas aulas práticas, é importante verificar qual a percepção dos estudantes em relação aos cursos extracurriculares.

\section{Metodologia}

A pesquisa de caráter qualitativo foi realizada pela aplicação de um questionário (anexo 1). O questionário anônimo era composto por 10 perguntas, sendo nove questões objetivas e uma questão dissertativa. As questões 3 e 4 não foram consideradas nesta análise, uma vez que eram direcionadas ao público egresso do curso, com o qual não se obteve contato. Foram aplicados 65 questionários, 35 no $2^{\circ}$ semestre e 30 no $4^{\circ}$ semestre.

Os resultados obtidos com as questões objetivas foram analisados na forma de porcentagem, enquanto o resultado da questão dissertativa foi enquadrado na análise de conteúdo e dividido em categoria de palavras. A análise de conteúdo permite, também, observar motivos de satisfação, insatisfação ou opiniões subentendidas e a natureza de problemas. Uma parte importante do comportamento, opinião ou ideias de pessoas se exprime sob a forma verbal ou escrita. 


\section{Resultados e discussão}

Os resultados indicam que 96,92\% dos alunos do Curso Técnico em Agropecuária do Colégio Politécnico UFSM consideram os cursos extracurriculares como relevantes na sua formação profissional. Quando comparamos os resultados obtidos entre alunos do inicio do curso $\left(2^{\circ}\right.$ semestre) e final de curso ( $4^{\circ}$ semestre), $96,07 \%$ e $100 \%$ respectivamente, observamos, ao contrário do esperado, uma concordância a respeito da importância desses cursos. Isso se deve, provavelmente, a qualidade e frequência com que cursos da formação complementar são oferecidos pelo colégio, uma vez que $69,23 \%$ dos alunos responderam que esses cursos são oferecidos frequentemente (mais de 3 vezes por semestre) pela instituição. Estas informações estão amplamente difundidas em currículos baseados na prática reflexiva, a qual se fundamenta em uma concepção ampliada de currículo, que inclui a participação em eventos e em cursos extracurriculares, atendendo e corroborando com os interesses dos discentes no auxílio para compor sua própria estrutura de conhecimento (Rangel-Betti; Betti, 1996).

Quanto aos alunos já terem participado de cursos extracurriculares, $86,27 \%$ dos alunos do $2^{\circ}$ semestre responderam já ter participado, contra $78,57 \%$ dos alunos do $4^{\circ}$ semestre. Embora com mais tempo de curso, os alunos do $4^{\circ}$ semestre participaram menos do que os alunos que iniciaram o curso mais tarde, mesmo que $100 \%$ dos alunos do final de curso tenham considerado que os cursos extracurriculares importantes pra a formação profissional. Isso pode ser explicado por uma menor oferta desses cursos durante a fase de estudos inicial destes alunos, uma vez que $58,15 \%$ dos alunos do $4^{\circ}$ semestre responderam que houve pouca ou nenhuma oferta desses cursos no colégio politécnico da UFSM. Neste aspecto, podemos explicar essa diferença entre os alunos do $2^{\circ}$ e $4^{\circ}$ semestre, principalmente, pela criação, pelo governo federal, do Pronatec em outubro de 2011, que correspondeu a incentivo para ofertar e ampliar a educação profissional e tecnológica. Assim, os estudantes hoje no $4^{\circ}$ semestre não foram contemplados com o incentivo deste programa desde o início do seu curso.

Em geral, a modalidade de curso teórico-prático, com $88,00 \%$ das respostas, foi a preferida pelos estudantes. Sendo $90,90 \%$ e $81,81 \%$ para $\circ 2^{\circ}$ e $4^{\circ}$ semestre. Em diferentes cursos extracurriculares a prática está presente, sendo uma forma que o discente encontra de exercer a profissão precocemente (Pares; Andrade, 2005). Nesse sentido, a relação teória-prática possibilita que o aluno esteja presente em situações problematizadoras e assim construa, pela prática, de um saber experimental (Winterhalter; Nogueira, 2012).

Quando questionados a respeito do assunto dos cursos extracurriculares oferecidos, a maioria dos estudantes $(81,54 \%)$ respondeu que os cursos atendiam seus interesses. Quando analisamos o início e fim do curso técnico, as respostas foram bem semelhantes, $82,35 \%$ e 78,57 para alunos do $2^{\circ}$ e $4^{\circ}$ semestre, respectivamente.

Ao questionarmos os estudantes sobre o objetivo dos cursos extracurriculares, se eles serviriam para complementar as disciplinas, abordar assuntos não vistos currículo do curso, ambas as opções ou nenhuma delas (não contribuem para a formação), quase dois terços dos estudantes $(64,62 \%)$ respondeu que os cursos extracurriculares serviam tanto como complemento, quanto para abordagem de novos assuntos. As atividades extracurriculares são indispensáveis para a complementação da formação acadêmica, 
como demonstra o estudo de Rego (1994) que trata sobre estágio extracurricular na prática médica, na qual os alunos podem desfrutar de uma autonomia que não precisa ser compatível com seu nível de formação. Os estudantes estão cada vez mais envolvidos nestas atividades devido, principalmente, à necessidade de aquisição de novas experiências que complementem o currículo, definição profissional e a urgência em vivenciar aprendizados significativos (Peres et al., 2007). Somente 3,08\% dos estudantes responderam que os cursos extracurriculares não contribuíam para a formação profissional.

Questionou-se, ainda, com uma questão de livre resposta, a importância dos cursos extracurriculares. Pela leitura das respostas obtivemos uma frequência de $90,77 \%$ das palavras importância dos "cursos extracurriculares", resultado bastante semelhante à questão 5 (96,92\%). Outras categorias de palavras identificadas foram o "aprendizado", apresentando uma frequência de $60,00 \%$ e $40,00 \%$ para o $2^{\circ}$ e $4^{\circ}$ semestre respectivamente; a "formação profissional - currículo" apresentando uma frequência de $26,67 \%$ e 25,00\%; "oportunidades de praticar", com percentual de 10,00\% e 20,00\% e também foi citado o interesse em "maior diversidade de cursos" $3,3 \%$ e $1,5 \%$. As categorias de palavras possibilitaram perceber o interesse dos estudantes por assuntos não abordados nas disciplinas e a demonstração da preocupação com o currículo.

Diferentemente dos dados obtidos pela maioria dos autores, foi observado que, tanto o segundo, quanto o quarto semestre do Curso Técnico em Agropecuária demonstraram o mesmo interesse nos cursos extracurriculares. Um fator que pode ter contribuído para este resultado pode ter sido o fato de que foi ofertado um curso extracurricular na área de interesse de grande parte dos alunos no mesmo semestre em que a pesquisa foi realizada, sendo que participaram desse curso, tanto estudantes do $2^{\circ}$, quanto do $4^{\circ}$ semestre. Esse curso pode ter despertado o interesse dos estudantes para a importância dos cursos extracurriculares.

\section{Referências}

BRASIL. Congresso Nacional. Lei federal n. 9.394 de 20 de dezembro de 1996. Estabelece as diretrizes e bases da educação nacional. Brasília: DOU de 22/12/1996

LEI N. 11.892, de 29 de dezembro de 2008. Institui a rede federal de educação profissional, científica e tecnológica, cria os institutos federais de educação, ciência e tecnologia e dá outras providências. Casa Civil, Brasília DF, 2008.

DELUIZ, Neise. Qualificação, competências e certificação: visão do mundo do trabalho. Revista Formação, Brasília, v. 1, n. 2, 2001, p. 7-17.

FREITAS, Henrique Mello Rodrigues; JANISSEK, Raquel. Análise léxica e análise do conteúdo: técnicas complementares, sequenciais e recorrentes para exploração de dados qualitativos. Porto Alegre: Sagra Luzato, 2000.

GONDIN, Sônia Maria Guedes. Perfil profissional e mercado de trabalho: relação com a formação acadêmica pela perspectiva de estudantes universitários. Estudos de Psicologia, Natal, v. 7, n. 2, 2002, p. 299-309.

MOROSINI, Marília Costa. Professor do ensino superior: identidade, docência e formação. Brasília: Inep, 2000.

PEREIRA, Alessandra Knoll; KOSHINO, Marcos Fernandes; FERREIRA, Talita Ribeiro, ROCHA; Rudimar Antunes. A importância das atividades extracurriculares universitárias 
para o alcance dos objetivos profissionais dos alunos de administração da Universidade Federal de Santa Catarina. Revista Gestão Universitária na América Latina. Florianópolis, v. 4, n. 3, 2011, p. 163-194.

PERES, Cristiane Martins. Atividades extracurriculares: Representações e vivencias durante a formação médica. Ribeirão Preto: USP, 2006. 243f. Dissertação (mestrado em Ciências). Programa de Pós-Graduação em Psicologia, Universidade de São Paulo.

PERES, Cristiane Martins; ANDRADE, Antônio Santos, GARCIA, Sérgio Britto. Atividades Extracurriculares: Multiplicidade e Diferenciação Necessárias ao Currículo. Revista Brasileira de Eduação Médica, Rio de Janeiro, v. 31, n. 3, 2007, p. 203-211.

PRONATEC. Política de atividades extracurriculares. Disponível em: <http://pronatec.mec. gov.br/index.php>. Acesso em: 19 mar. 2014.

RAMOS, Viviane Silva. Desenvolvimento local e território: uma reflexão sobre o papel dos Institutos Federais de Educação Ciência e Tecnologia. Seropédica: UFRRJ, 2011. $79 f$. Dissertação (mestrado em Ciências). Programa de Pós-Graduação em Educação Agrícola, Universidade Federal Rural do Rio de Janeiro.

REGO, S. T. A. A prática na formação médica: o estágio extracurricular em questão. Rio de Janeiro: Uerj, 1994. Dissertação (mestrado em Saúde Coletiva). Instituto de Medicina Social, Universidade do Estado do Rio de Janeiro.

RANGEL-BETTI, Irene; BETTI, Mauro. Novas perspectivas na formação profissional em educação física. Revista Motriz, Rio Claro, v. 2, n. 1, 1996, p. 10-15.

WINTERHALTER, Diolinda Franciele; NOGUEIRA, Valdir. As contribuições do estágio extracurricular para formação docente. SIMPÓSIO DE ENSINO PESQUISA E EXTENSÃO, 14, 2012. Anais ... Santa Maria: Unifra, 2012. 
ANEXO 1.

\section{UNIVERSIDADE FEDERAL DE SANTA MARIA \\ CENTRO DE EDUCAÇÃO \\ PROGRAMA ESPECIAL DE FORMAÇÃO DE PROFESSORES PARA EDUCAÇÃO \\ PROFISSIONAL}

Importância dos Cursos Extracurriculares na Formação Profissional dos Acadêmicos do Curso Técnico em Agropecuária

Assunto:Visão dos estudantes a respeito dos cursos extracurriculares, no início e no final da sua formação técnica

Objetivo: Constatar a importância dos cursos extracurriculares para formação do professional técnico em agropecuária durante a formação no colégio politécnico da Universidade Federal de Santa Maria

\section{Questionário:}

1. Assinale sua formação acadêmica atual:

( ) Segundo semestre

( ) Quarto semestre

( ) Formado

- Caso não tenha concluído o curso ainda, vá direto para a pergunta 5. E os já formado por favor responder todo o questionário.

2. A quanto tempo (anos) concluiu o curso técnico em agropecuária: anos

3. Você atua como técnico em agropecuária?

( ) $\mathrm{Sim}$

( ) Não

4. Caso não atue como técnico em agropecuária, explique o motivo:

5. Você considera/considerou os coursos extracurriculares importantes para sua formação profissional?
( ) $\mathrm{Sim}$
( ) Indiferente
( ) Não

6. Você já participou de algum curso extracurricular?

( ) $\mathrm{Sim}$

( ) Não 
7. Caso sua resposta seja afirmativa na questão 6 responda esta pergunta.

Você considera mais importante e proveitoso que tipo de curso:

( ) Apenas teórico

( ) Apenas prático

( ) Teórico e prático

8. São/foram ofertados cursos extracurriculares no técnico em agropecuária na sua instituição?

( ) Com alta frequência (3 ou mais por semestre)

( ) Com baixa frequência (menos que 3 por semester)

( ) Nunca

9. Os cursos extracurriculares ofertados são da sua area de interesse?

( ) $\operatorname{Sim}$

( ) Não

10. Os cursos extracurriculares quando ofertados:

( ) Complementam as disciplinas

( ) Abordam assuntos não vistos durante as disciplinas

( ) Ambas alternativas anteriores

( ) Não contribuem para a formação

11. Considerando sua formação atual, dentro do curso técnico em agropecuária, qual seu ponto de vista a respeito dos cursos extracurriculares e por que?

Karina Gutierrez é estudante do curso de doutorado em Animal Science of McGill University, Canada.

Endereço: Room MS1-089, Macdonald-Stewart Building 21,111 Lakeshore Road. Ste. Anne de Bellevue, Quebec - Canada.

E-mail: kahguti@gmail.com.

Joabel Tonellotto dos Santos é estudante de doutorado do Programa de PósGraduação em Medicina Veterinária da Universidade Federal de Santa Maria.

Endereço: Avenida Roraima, 1000 - Hospital Veterinário - Laboratório de Biotecnologia e Reprodução Animal, sala 400 - 97105-900 - Santa Maria - RS Brasil.

E-mail: joabelts@yahoo.com.br.

Matheus Pedrotti De Cesaro é estudante de doutorado do Programa de PósGraduação em Medicina Veterinária da Universidade Federal de Santa Maria.

Endereço: Avenida Roraima, 1000 - Hospital Veterinário - Laboratório de Biotecnologia e Reprodução Animal, sala 400 - 97105-900 - Santa Maria - RS Brasil.

E-mail:vetmatheus@hotmail.com. 
Paulo Roberto Antunes da Rosa é estudante de doutorado do Programa de PósGraduação em Medicina Veterinária, Universidade Federal de Santa Maria.

Endereço: Avenida Roraima, 1000 - Hospital Veterinário - Laboratório de Biotecnologia e Reprodução Animal, sala 400 - 97105-900 - Santa Maria - RS Brasil.

E-mail: robertoadr@yahoo.com.br.

Leila Maria Araújo Santos é professor na Universidade Federal de Santa Maria. Endereço: Avenida Roraima, 1000 - Colégio Técnico Industrial de Santa Maria 97105-900 - Santa Maria - RS - Brasil.

E-mail: leilamas@terra.com.br.

Recebido em 27 de março de 2014.

Aceito em 14 de abril de 2014. 